\title{
Melanoma-associated antigen-A1 expression predicts resistance to docetaxel and paclitaxel in advanced and recurrent gastric cancer
}

\author{
TAKAHISA SUZUKI $^{1}$, KAZUHIRO YOSHIDA $^{1}$, YOSHIYUKI WADA ${ }^{1}$, YOICHI HAMAI ${ }^{1}$, \\ KAZUHIRO SENTANI ${ }^{2}$, NAOHIDE OUE $^{2}$ and WATARU YASUI ${ }^{2}$ \\ ${ }^{1}$ Department of Surgical Oncology, Research Institute for Radiation Biology and Medicine, Hiroshima University; \\ ${ }^{2}$ Department of Molecular Pathology, Hiroshima University Graduate School of Biomedical Sciences, Hiroshima, Japan
}

Received February 26, 2007; Accepted May 14, 2007

\begin{abstract}
Melanoma-associated antigen (MAGE) genes are cancer-testis antigen genes that serve as immunotherapy targets in several human cancers. Previous studies have revealed that the forced expression of MAGE genes induces a paclitaxelresistant phenotype. In the present study, we examined whether the expression of MAGE-A1 could predict the response of advanced and recurrent gastric cancers (GCs) to taxan (docetaxel or paclitaxel)-based chemotherapy. The expression of MAGE-A1 was analyzed by immunostaining in 41 primary GC samples. DNA demethylation was assessed by methylationspecific polymerase chain reaction and the effect of the forced expression of MAGE-A1 on drug resistance to taxan drugs was monitored by MTT assay. The expression of MAGE-A1 in primary GC was observed in $4(9.8 \%)$ of 41 cases. All 4 patients with MAGE-A1-positive GC showed progressive disease, whereas MAGE-A1 expression was not detected in any of the 23 patients showing partial response $(\mathrm{P}=0.0302)$. There was no association between MAGE-Al gene demethylation and response to chemotherapy $(\mathrm{P}=0.7245)$. The forced MAGE-A1 expression in the TMK-1 GC cell line increased the sensitivity to paclitaxel and docetaxel. These results suggest that although MAGE-A1 does not participate directly in the drug-resistant phenotype, the expression of MAGE-A1 could be a marker for the prediction of resistance to taxan-based chemotherapies in patients with GC.
\end{abstract}

\section{Introduction}

Gastric cancer (GC) is one of the most common cancers worldwide. Despite improvements in cancer diagnosis and therapy, many patients are still diagnosed at the late stages of

Correspondence to: Dr Wataru Yasui, Department of Molecular Pathology, Hiroshima University Graduate School of Biomedical Sciences, 1-2-3 Kasumi, Minami-ku, Hiroshima 734-8551, Japan E-mail:wyasui@hiroshima-u.ac.jp

Key words: DNA methylation, DNA demethylation, melanomaassociated antigen-A1, serial analysis of gene expression, gastric cancer the disease, and the disease often recurs even after curative surgery. Until recently, GC was considered a poorly chemoresponsive cancer. However, several clinical trials have shown that certain chemotherapeutic agents are quite effective against GC. We recently reported that a combination of docetaxel and $\mathrm{S}-1$ is active against metastatic $\mathrm{GC}(1,2)$. The taxoids, paclitaxel (taxol) and docetaxel (taxotere), are promising antitumor compounds. Paclitaxel and docetaxel work as mitotic spindle toxins, that stabilize microtubules and enhance microtubule polymerization, resulting in the mitotic arrest of tumor cells (3). S-1 is an oral fluorouracil antitumor drug that contains a combination of three pharmacological agents. Although combination chemotherapy with docetaxel and S-1 has shown a high degree of efficacy against GC (4), some patients have shown a poor response, possibly due to the inefficiency of the chemotherapy. For effective treatment, the identification of patients who will respond well to a specific chemotherapy could be important. Therefore, there is an urgent need for new biomarkers for GC chemotherapy.

Cancer develops as a result of multiple genetic and epigenetic alterations $(5,6)$. Better knowledge of the changes in gene expression that occur during gastric carcinogenesis could lead to improvements in diagnosis, treatment and prevention. In order to identify potential molecular markers for GC and to better understand the development of GC at the molecular level, comprehensive analyses of gene expression could be useful (7). We previously performed serial analysis of gene expression (SAGE) of 4 primary GCs (8) and identified several GC-specific genes (9). Of these genes, taxol (also known as paclitaxel) resistance associated gene 3 [TRAG3, also known as CSAG family, member 2 (CSAG2)] is a candidate gene for cancer-specific expression, at least in patients with GC. TRAG3 was originally identified by the differential gene expression of SKOV-3 and its taxol-resistant subline, SKOV-3 $3_{\mathrm{TR}}$. However, the expression of endogenous TRAG3 in taxol-sensitive cell lines does not confer taxol resistance, suggesting that TRAG3 does not participate directly in the taxol-resistant phenotype (10). TRAG3 is a cancer-testis antigen and is overexpressed in malignant melanoma (11), colorectal (12), lung (13), and breast cancer (14). Although TRAG3 has been identified as a T-lymphocyte epitope (15), the biological function of TRAG3 is poorly understood. TRAG3 is located on chromosome $\mathrm{Xq} 28$ and is flanked by the melanoma-associated antigen (MAGE) gene 
cluster, which includes $M A G E-2,3,4,5,10$, and 12. It has been reported that both MAGE-2 (also known as MAGE-A2) and MAGE-6 (also known as MAGE-A6) transfectants demonstrate a 4-fold increase in resistance to paclitaxel (16). Therefore, the acquisition of paclitaxel resistance could be associated with the increased expression of MAGE but not TRAG3. MAGE genes are considered tumor-specific antigens and ideal targets for cancer immunotherapy (17) as they are expressed in a large variety of neoplastic lesions and only in the testes in healthy adults (18). However, the clinical utility of the expression of MAGE genes for the prediction of chemosensitivity has not been investigated in cancers including GC.

In the present retrospective study, the relationship between the expression of MAGE-Al (also known as MAGE-1) and the response of advanced and recurrent GCs to chemotherapy with paclitaxel or docetaxel was investigated. As the expression of MAGE-Al is activated by DNA demethylation in GC (19), the DNA methylation status of $M A G E-A l$ was also analyzed by methylation-specific polymerase chain reaction (PCR).

\section{Patients and methods}

Patients and tumor specimens. The subjects were 41 patients with GC referred to the Department of Surgical Oncology, Hiroshima University Hospital (Hiroshima, Japan). Forty-one GC tissue samples and 41 corresponding non-neoplastic mucosa samples from these 41 patients were analyzed for the expression and DNA methylation of $M A G E-A 1$. The GC and the corresponding non-neoplastic mucosa samples were obtained by resection or biopsy before the initiation of chemotherapy. All 41 specimens were archival, formalin-fixed, paraffin-embedded tissues. We confirmed microscopically that the tumor tissue specimens consisted mainly $(>50 \%)$ of cancer cells and that the non-neoplastic mucosae did not show any evidence of tumor cell invasion or significant inflammatory involvement. All patients were determined to have inoperable or recurrent GC. Of the 41 patients, 12 were treated with paclitaxel alone; the remaining 29 were treated with a combination of docetaxel and S-1.

Paclitaxel $(80 \mathrm{mg} / \mathrm{m} 2)$ was infused over $1 \mathrm{~h}$ on days 1,8 , and 15 , followed by a 1 -week interval ( 1 cycle). For the combination therapy of S-1 and docetaxel (2), S-1 was administered orally at a dose of $80 \mathrm{mg} / \mathrm{m}^{2}$ within $30 \mathrm{~min}$ of the morning and evening meals for 2 weeks, followed by a 1 week interval (1 cycle). Docetaxel $\left(40 \mathrm{mg} / \mathrm{m}^{2}\right)$ in $100 \mathrm{ml}$ $0.9 \%$ saline was infused over $1 \mathrm{~h}$ on the morning of day 1 . This cycle of administration was repeated every 3 weeks, and the infusion was started at the same time as the S-1 administration.

All 41 patients provided a medical history and underwent a physical examination including an evaluation of performance status, complete blood cell count (CBC), serum chemistry profile, creatinine clearance, urinalysis, electrocardiography, chest X-ray, and computed tomography (CT) and/or magnetic resonance imaging at the time of enrollment. An upper GI series, gastrointestinal fiberscopy (GIF), and barium enema were performed if necessary. A baseline biological analysis (CBC, serum chemistry profile and urinalysis) and a physical examination, including the determination of weight and performance status, was performed at least weekly while the patients were undergoing treatment. Tumor markers, including CEA and CA19-9, were checked once each month.

The responses of the primary and metastatic lesions to treatment were assessed according to the World Health Organization criteria. The primary and metastatic lesions were evaluated by GIF, CT, ultrasonography, and other radiographic examinations. Complete response (CR) was defined as the absence of all evidence of cancer for $<4$ weeks. Partial response (PR) was defined as at least $50 \%$ reduction in the sum of the products of the perpendicular diameters of all lesions for $<4$ weeks without any evidence of new lesions or the progression of existing lesions. No change (NC) was defined as $<50 \%$ reduction or $<25 \%$ increase in the sum of the products of the perpendicular diameters of all lesions without any evidence of new lesions. Progressive disease (PD) was defined as $>25 \%$ increase in $<1$ lesion or the appearance of new lesions. Of the 12 patients treated with paclitaxel alone, none showed CR, 4 showed PR, 5 showed $\mathrm{NC}$, and 3 showed PD. Of the 29 patients treated with the combination of docetaxel and S-1, none showed CR, 19 showed PR, 4 showed NC, and 6 showed PD.

Histological classification (intestinal-type or diffuse-type) was performed according to the Lauren classification system (20). Tumor staging was according to the TNM staging system (21). As written informed consent had not been obtained for the use of some samples, the identifying information was removed from all the samples prior to analysis to protect patient privacy. This procedure was in accordance with the Ethical Guidelines for Human Genome/Gene Research enacted by the Japanese Government.

Immunohistochemistry. Formalin-fixed, paraffin-embedded samples (primary GC) were sectioned, deparaffinized, stained with $H \& E$, and evaluated to ensure that the sectioned block contained tumor cells. Adjacent sections were then stained immunohistochemically. For immunostaining of MAGE-A1, a Dako LSAB Kit (Dako, Carpinteria, CA, USA) was used according to the manufacturer's recommendations. In brief, the sections were pretreated by microwaving them in citrate buffer for $30 \mathrm{~min}$ to retrieve antigenicity. After peroxidase activity was blocked with $3 \% \mathrm{H}_{2} \mathrm{O}_{2}$-methanol for $10 \mathrm{~min}$, the sections were incubated with normal goat serum (Dako) for 20 min to block nonspecific antibody binding sites. Anti-MAGE-1 antibody (6C1, 1:100, Novocastra, Newcastle, UK) was incubated with tissue samples for $60 \mathrm{~min}$ at room temperature, followed by incubations with biotinylated anti-rabbit/mouse IgG and peroxidase-labeled streptavidin for $10 \mathrm{~min}$ each. Staining was completed with a 10 -min incubation with the substrate-chromogen solution. The sections were counterstained with $0.1 \%$ hematoxylin. The $6 \mathrm{C} 1$ antibody recognizes both the MAGE-A 1 protein and the MAGE-A10 protein (22). It has been confirmed that MAGE-A10 is present in the nucleus, whereas MAGE-A1 is localized in the cytoplasm (22). Therefore, cytoplasmic staining was considered positive for MAGE-A1, and nuclear staining was disregarded in the present study.

Genomic DNA extraction and methylation-specific PCR $(M S P)$. For DNA extraction from the archival, formalin-fixed, paraffin-embedded tissue samples, primary GC samples and 

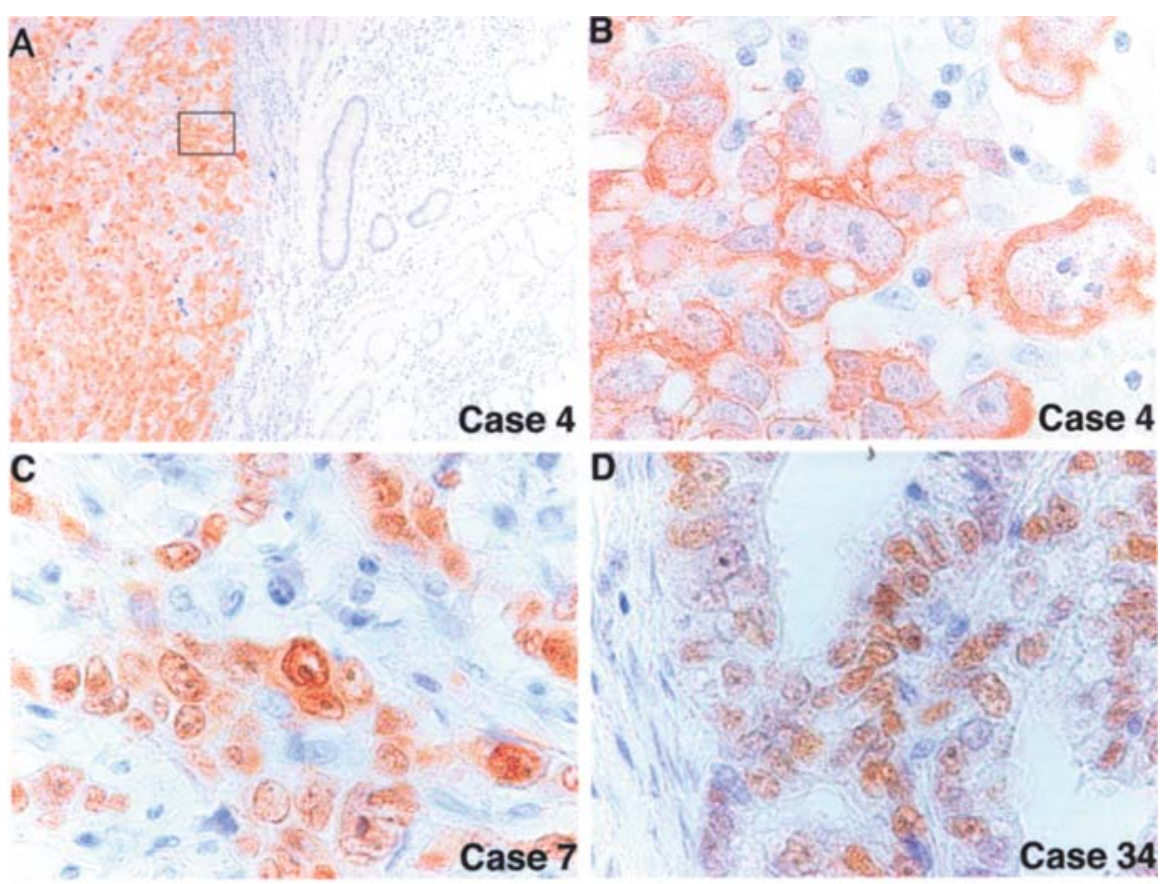

E
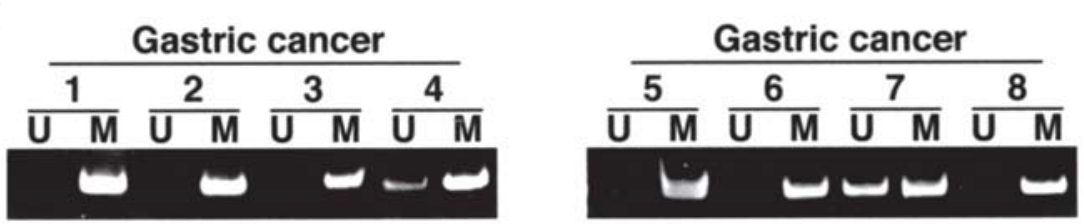

Figure 1. Melanoma-associated antigen-A1 (MAGE-A1) expression in gastric cancer (GC). (A) Sections of GC and the corresponding non-neoplastic mucosae were immunostained with monoclonal antibody $6 \mathrm{C} 1$. In the corresponding non-neoplastic gastric mucosae, no staining was detected, whereas strong and extensive staining was observed in the GC cells (original magnification, x100). Panel (B) is a high-magnification view of the field indicated by the box in panel (A) (original magnification, x1000). Only cytoplasmic staining is visible in Case 4, and therefore, this case was considered positive for MAGE-A1 expression. Stromal cells were not stained. (C) In Case 7, both the nuclear and cytoplasmic staining of MAGE-A1 were observed. GC cases showing both cytoplasmic and nuclear staining were considered positive for MAGE-A1 immunostaining (original magnification, x1000). (D) In Case 34, only nuclear staining is visible. GC cases showing only nuclear staining were considered negative for MAGE-A1 expression (original magnification, $\mathrm{x} 1000$ ). (E) DNA methylation analyses of MAGE-Al in the GC tissues by methylation-specific polymerase chain reaction (MSP). Primer sets were used, unmethylated (U), methylated (M). The methylated allele was present in all the cases. The unmethylated allele was detected in Cases 4 and 7 . The expression of MAGE-A1 was observed in Cases $4(\mathrm{~B})$ and 7 (C) by immunostaining.

corresponding non-neoplastic samples were manually dissected with a fine needle from different sets of 10 serial, $10-\mu \mathrm{m}$ thick, formalin-fixed, paraffin-embedded tissue sections. The dissected samples were lysed by incubation in $200 \mathrm{mg} / \mathrm{ml}$ proteinase $\mathrm{K}$ at $55^{\circ} \mathrm{C}$ for 3 days. Genomic DNA was purified by 3 rounds of phenol/chloroform extraction followed by ethanol precipitation. In order to examine DNA methylation patterns, genomic DNA was treated with $3 \mathrm{M}$ sodium bisulfite as described previously (23). For analysis of DNA methylation of the MAGE-Al gene, MSP was performed as described previously (19). The PCR products $(15 \mu 1)$ were separated on $8 \%$ non-denaturing polyacrylamide gels, stained with ethidium bromide, and visualized under ultraviolet light.

Cell lines, expression vector, and transfection. The TMK-1 GC cell line was established in our laboratory (24). All cell lines were maintained in RPMI-1640 (Nissui Pharmaceutical, Tokyo, Japan) containing 10\% fetal bovine serum (Whittaker, Walkersville, MD, USA) in a humidified atmosphere of 5\% $\mathrm{CO}_{2}$ and $95 \%$ air at $37^{\circ} \mathrm{C}$. For constitutive expression of the $M A G E-A 1$ gene, cDNA was PCR amplified and subcloned into pcDNA 3.1 (Invitrogen, Carlsbad, CA, USA). The pcDNA-MAGE-A1 expression vector was transfected into TMK-1 cells with FuGENE6 (Roche Diagnostics, Indianapolis, IN, USA) according to the manufacturer's instructions. Stable transfectants were selected after 2 weeks of culture with $80 \mu \mathrm{g} /$ ml G418 (Invitrogen).

Western blot analysis. The preparation of whole-cell lysates and Western blot analysis were performed as described previously (25). Protein concentrations were determined by the Bradford protein assay (Bio-Rad, Richmond, CA, USA) with bovine serum albumin used as the standard. Lysates (40 $\mu \mathrm{g}$ ) were solubilized in Laemmli's sample buffer by boiling and then subjected to $10 \%$ SDS-polyacrylamide gel electrophoresis followed by electrotransfer onto a nitrocellulose filter. The filter was incubated for $1 \mathrm{~h}$ at room temperature with an anti-MAGE-A1 antibody. Peroxidaseconjugated anti-mouse IgG was used in the secondary reaction. The immunocomplexes were visualized with an ECL Western Blot Detection System (Amersham Biosciences, Piscataway, NJ, USA). The quality and amounts of proteins 
on the gel were confirmed by detection with an anti-ß-actin antibody (Sigma Chemical Co., St. Louis, MO, USA).

Drug treatment and cell growth assay. Docetaxel was obtained from Rhone-Poulenc Rorer (Antony, France). Paclitaxel and mitomycin $\mathrm{C}$ were purchased from Sigma. Cell growth was assessed by a standard 3-(4,5-dimethyl-2-tetrazolyl)-2,5diphenyl-2H tetrazoluim bromide (MTT) assay as described previously (4). In brief, GC cells were seeded into 96-well culture plates. After 24-h incubation, the cells were incubated for $72 \mathrm{~h}$ at $37^{\circ} \mathrm{C}$ with varied drug concentrations (0.1-100 nM docetaxel, 0.1-100 $\mathrm{nM}$ paclitaxel, and 0.01-10 $\mu \mathrm{M}$ mitomycin C). After incubation, $10 \mu 1 \mathrm{MTT}$ (Sigma) solution $(5 \mathrm{mg} / \mathrm{ml})$ were added to each well, and the plates were incubated for $3 \mathrm{~h}$ at $37^{\circ} \mathrm{C}$. The growth medium was then replaced with $150 \mu 1$ dimethyl sulfoxide (Wako, Tokyo, Japan) per well, and the absorbance at $540 \mathrm{~nm}$ was measured with a Titertek Multiscan.

Statistical methods. Differences were analyzed by Fisher's exact test. P-values $<0.05$ were considered statistically significant.

\section{Results}

Relationship between MAGE-Al expression and response of $G C$ to paclitaxel and the combination of docetaxel and $S-1$. The expression and distribution of MAGE-A1 was investigated by immunostaining of $41 \mathrm{GC}$ tissues. MAGE-A1 was not stained in the corresponding non-neoplastic mucosae (Fig. 1A). Three GCs showed only cytoplasmic staining of MAGE-A1 (Fig. 1B) and both cytoplasmic and nuclear staining were observed in one GC (Fig. 1C). One GC showed only nuclear staining (Fig. 1D). As described in 'Materials and methods', cytoplasmic staining was considered positive for MAGE-A1 expression and nuclear staining was disregarded. In total, MAGE-A1 staining was observed in $4(9.8 \%)$ of the $41 \mathrm{GC}$ tissues. In all the 4 cases, $>50 \%$ of the cancer cells were stained, and in the remaining 37 cases, no expression of MAGE-A1 was observed. We considered that all the 4 cases were positive for MAGE-A1. The expression of MAGE-A1 was not associated with age or sex (data not shown). There was no clear association between MAGE-A1 expression and the clinicopathological characteristics in the group of $20 \mathrm{GC}$ cases obtained by resection (Table I). Of the 12 patients treated with paclitaxel alone, the 2 MAGE-A1-positive patients showed PD in response to paclitaxel, whereas 4 of the 10 MAGE-A1-negative patients showed PR. Of the 29 patients treated with a combination of docetaxel and S-1, the 2 MAGE-A1-positive patients showed PD, whereas 19 of the 27 MAGE-A1-negative patients showed PR. In total, the 4 patients with MAGE-A1-positive GC showed PD in response to taxan-based chemotherapy, and the expression of MAGEA1 was not detected in the 23 patients showing PR to the taxan-based chemotherapy $(\mathrm{P}=0.0302$, Table II). These findings indicate that the expression of MAGE-A1 is a marker for the response to taxan-based chemotherapy.

Relationship between DNA methylation of the MAGE-A1 gene and response of GC to paclitaxel and combination therapy of docetaxel and $S-1$. We investigated the DNA methylation status of the $M A G E-A l$ gene as the expression of
Table I. Relationship between MAGE-A1 protein expression and clinicopathological characteristics in GC.

$\frac{\text { MAGE-A1 expression }}{\begin{array}{c}\text { Positive Negative } \\ (\%)\end{array}}$ P-value ${ }^{\mathrm{a}}$

(\%)

\begin{tabular}{llrr}
\hline T grade & & & \\
T1/2/3 & $1(7.1)$ & 13 & 0.2018 \\
T4 & $2(33.3)$ & 4 & \\
N grade & & & \\
N0/1/2 & $1(9.1)$ & 10 & 0.5658 \\
N3 & $2(22.2)$ & 7 & \\
Liver metastasis & & & \\
Present & $0(0)$ & 5 & 0.5395 \\
Absent & $3(20)$ & 12 & \\
Peritoneal dissemination & & & \\
Present & $1(16.7)$ & 5 & 1.0000 \\
Absent & $2(14.3)$ & 12 & \\
Distant metastasis & & & \\
Present & & & \\
Absent & $0(0)$ & 0 & ND \\
Stage & $3(15)$ & 17 & \\
I/II/III & & & \\
IV & $1(14.3)$ & 6 & 1.0000 \\
Histology & $2(15.4)$ & 11 & \\
Intestinal & & & \\
Diffuse & $1(25)$ & 3 & 1.0000 \\
\hline
\end{tabular}

MAGE-A1, melanoma-associated antigen-A1; GC, gastric cancer;

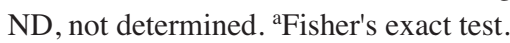

Table II. Association between MAGE-A1 expression and response to taxan-based chemotherapy.

\begin{tabular}{lccc}
\hline Response & $\begin{array}{c}\text { No. of } \\
\text { cases }\end{array}$ & $\begin{array}{c}\text { No. of MAGE-A1- } \\
\text { positive cases (\%) }\end{array}$ & P-value \\
\hline CR & 0 & $0(0)$ & 0.0302 \\
PR & 23 & $0(0)$ & \\
NC & 9 & $0(0)$ & \\
PD & 9 & $4(44.4)$ & \\
\hline
\end{tabular}

MAGE-A1, melanoma-associated antigen-A1; CR, complete response; $\mathrm{PR}$, partial response; $\mathrm{NC}$, no change; $\mathrm{PD}$, progressive

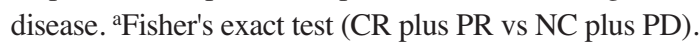

$M A G E-A 1$ is activated by DNA demethylation in GC (19). Representative results of MSP are shown in Fig. 1E. In total, the DNA demethylation of $M A G E-A l$ was detected in 10 
Table III. Relationship between DNA demethylation of $M A G E-A l$ and clinicopathological characteristics in GC.

\begin{tabular}{|c|c|c|c|}
\hline & \multicolumn{2}{|c|}{$\begin{array}{c}M A G E-A l \\
\text { methylation status }\end{array}$} & \multirow[b]{2}{*}{ P-value } \\
\hline & $\begin{array}{l}\text { Demethyl- } \\
\text { ated }(\%)\end{array}$ & $\begin{array}{l}\text { Methyl- } \\
\text { ated }\end{array}$ & \\
\hline \multicolumn{4}{|l|}{$\mathrm{T}$ grade } \\
\hline $\mathrm{T} 1 / 2 / 3$ & $3(21.4)$ & 11 & 0.3027 \\
\hline $\mathrm{T} 4$ & $3(50)$ & 3 & \\
\hline \multicolumn{4}{|l|}{$\mathrm{N}$ grade } \\
\hline $\mathrm{N} 0 / 1 / 2$ & $4(36.4)$ & 7 & 0.6424 \\
\hline N3 & $2(22.2)$ & 7 & \\
\hline \multicolumn{4}{|c|}{ Liver metastasis } \\
\hline Present & $1(20)$ & 4 & 1.0000 \\
\hline Absent & $5(33.3)$ & 10 & \\
\hline \multicolumn{4}{|c|}{ Peritoneal dissemination } \\
\hline Present & $2(33.3)$ & 4 & 1.0000 \\
\hline Absent & $4(28.6)$ & 10 & \\
\hline \multicolumn{4}{|c|}{ Distant metastasis } \\
\hline Present & $0(0)$ & 0 & ND \\
\hline Absent & $6(30)$ & 14 & \\
\hline \multicolumn{4}{|l|}{ Stage } \\
\hline I/II/III & $2(28.6)$ & 5 & 1.0000 \\
\hline IV & $4(30.8)$ & 9 & \\
\hline \multicolumn{4}{|l|}{ Histology } \\
\hline Intestinal & $0(0)$ & 4 & 1.0000 \\
\hline Diffuse & $3(18.8)$ & 13 & \\
\hline
\end{tabular}

MAGE-A1, melanoma-associated antigen-A1; GC, gastric cancer; ND, not determined. ${ }^{a}$ Fisher's exact test.

Table IV. Relationship between DNA demethylation of $M A G E-A 1$ and expression of MAGE-A1.

\begin{tabular}{lccc}
\hline & \multicolumn{2}{c}{$M A G E-A 1$ methylation status } & \\
\cline { 2 - 3 } $\begin{array}{l}\text { MAGE-A1 } \\
\text { expression }\end{array}$ & $\begin{array}{c}\text { Demethyl- } \\
\text { ated (\%) }\end{array}$ & $\begin{array}{c}\text { Methyl- } \\
\text { ated }\end{array}$ & P-value \\
\hline Positive & $4(100)$ & 0 & 0.034 \\
Negative & $6(16.2)$ & 31 & \\
\hline
\end{tabular}

MAGE-A1, melanoma-associated antigen-A1. ${ }^{a}$ Fisher's exact test.

(24.4\%) of the $41 \mathrm{GC}$ samples. The demethylation of MAGEAl was not associated with patient age or sex (data not shown). There was no clear association between the demethylation of $M A G E-A l$ and clinicopathological characteristics in the group of $20 \mathrm{GC}$ cases obtained by resection (Table III).
Table V. Association between demethylation of MAGE-AI and response to taxan-based chemotherapy.

\begin{tabular}{lccc}
\hline Response & $\begin{array}{c}\text { No. of } \\
\text { cases }\end{array}$ & $\begin{array}{c}\text { No. of cases with } \\
\text { demethylation of } \\
\text { MAGE-Al (\%) }\end{array}$ & P-value $^{\text {a }}$ \\
\hline CR & 0 & $0(0)$ & 0.7245 \\
PR & 23 & $5(21.7)$ & \\
NC & 9 & $1(11.1)$ & \\
PD & 9 & $4(44.4)$ & \\
\hline
\end{tabular}

MAGE-A1, melanoma-associated antigen-A1; CR, complete response; $\mathrm{PR}$, partial response; $\mathrm{NC}$, no change; $\mathrm{PD}$, progressive

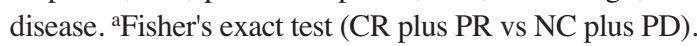

$M A G E-A 1$ was demethylated in 4 MAGE-A1-positive GC cases, whereas the demethylation of $M A G E-A l$ was detected in 6 of the 37 MAGE-A1-negative cases $(16.2 \%, \mathrm{P}=0.0021$, Table IV). There was no clear association between the $M A G E-A 1$ methylation status and the response to therapy in the group of 12 patients treated with paclitaxel alone, in the group of 29 patients treated with a combination of docetaxel and $\mathrm{S}-1$, or in the total 41 patients $(\mathrm{P}=0.7245$, Table $\mathrm{V})$.

Effect of forced MAGE-Al expression of GC cell line. As we detected a statistically significant association between MAGE-A1 expression and the response to taxan-based chemotherapy, we investigated the effect of forced MAGEA1 expression on chemoresistance in a GC cell line, TMK-1. TMK-1 cells were stably transfected with a vector expressing MAGE-A1. TMK-1 cells were selected due to their low endogenous MAGE-A1 expression (data not shown). Clones were selected in G418 and examined for MAGE-A1 expression by Western blotting. Four clones that expressed MAGE-A1 at significantly higher levels than the empty vector-transfected cells were isolated (Fig. 2A). In order to determine the effect of MAGE-A1 expression on cell growth, we performed MTT assays. The rate of cell growth of the TMK-1 cells expressing higher levels of MAGE-A1 did not differ from that of the cells transfected with the empty vector up to day 2 (data not shown). We then examined the effect of MAGE-A1 expression on paclitaxel or docetaxel sensitivity. Contrary to our expectation, the $\mathrm{IC}_{50}$ levels for both paclitaxel and docetaxel in the MAGE-A1-transfected cells were lower than those of the empty vector-transfected cells (Fig. 2B). The mitomycin $\mathrm{C} \mathrm{IC}_{50}$ levels did not differ significantly between the MAGE-A1-transfected cells and the empty vector-transfected cells.

\section{Discussion}

Previous data have suggested that the resistance to paclitaxel is associated with the increased expression of a variety of genes, including some that are localized near the cancer-testis genes (16). In the present study, we found that the expression of the protein encoded by the $M A G E-A l$ gene, which neighbors the cancer-testis antigen genes, was associated with the 
A

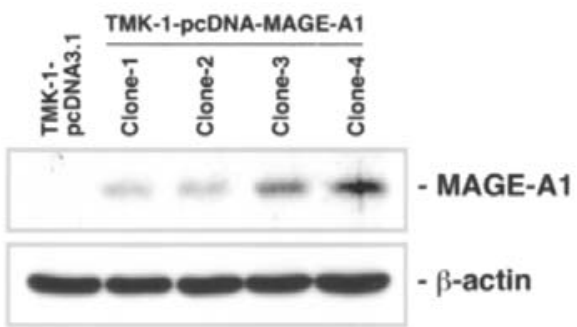

B

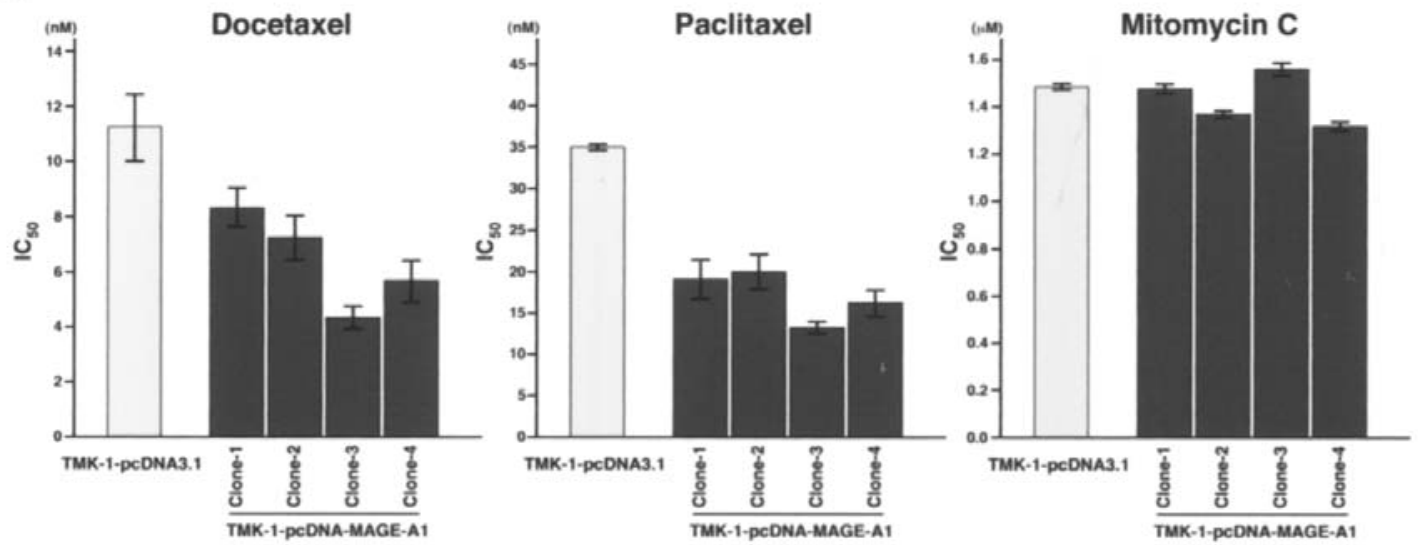

Figure 2. Effect of forced melanoma-associated antigen-A1 (MAGE-A1) expression on drug sensitivity. (A) Western blot analysis of the TMK-1 gastric cancer cell line stably transfected with the vector expressing MAGE-A1. Four G418-resistant clones overexpressing the MAGE-A1 protein, were isolated. (B) Drug sensitivity of MAGE-A1-transfected cells. MTT analysis revealed that forced MAGE-A1 expression increases the sensitivity to docetaxel and paclitaxel but does not change relative resistance to mitomycin $\mathrm{C}$.

response of GC to taxan-based chemotherapy. All 4 patients with MAGE-A1-positive GC showed PD in response to paclitaxel or combination chemotherapy of docetaxel and S-1. These findings indicate that the expression of MAGE-A1 is a marker for the response to taxan-based chemotherapy. It is important to note that of the 29 patients treated with a combination of docetaxel and S-1, the response to chemotherapy could have been more influenced by S-1 than taxan. The influence of MAGE-A1 expression on the response to S-1 should be examined.

The cancer-specific expression of MAGE-A1 has been reported in several cancers including GC (26-28). It has been reported that the MAGE-A1 protein expression is associated with invasiveness, lymph node metastasis, advanced pathological stage, and poor prognosis (29). It has also been reported that the demethylation of both $M A G E-A 1$ and MAGE-A3 occurs during the progressive stages of GC (19). In the present study, there was no clear association between MAGE-A1 expression/demethylation and the clinicopathological characteristics in the group of $20 \mathrm{GC}$ cases obtained by resection. As we analyzed a limited number of GC samples, additional experiments are needed. MAGE-Al gene-encoded peptides are recognized by cytotoxic $\mathrm{T}$ lymphocytes (30), and clinical trials of cancer-specific immunotherapies against MAGEA1-positive cells are underway. As taxan-based chemotherapies had no significant effects in the patients with MAGE-A1-positive GC in the present study, immunotherapy with antigen-presenting cells pulsed with MAGE-1 peptides could be an effective treatment for these patients.
DNA demethylation of the $M A G E-A l$ gene was not associated with response to taxan-based chemotherapy. The hypermethylation of $\mathrm{CpG}$ islands is associated with the transcriptional silencing of several genes and has been proposed as a mechanism for the inactivation of tumor suppressor genes and tumor-related genes in human cancers (31). The identification of methylated genes could be useful for diagnosis and treatment of cancer and could provide insight into the process of carcinogenesis. In GC, several tumor suppressor and tumor-related genes have been shown to be inactivated by promoter hypermethylation $(32,33)$, and DNA methylation increases with the progression of GC (34). Although the expression of MAGE-A1 was observed frequently in GCs with DNA demethylation of the $M A G E-A l$ gene, we found 6 GC samples with $M A G E-A 1$ gene demethylation that did not express the MAGE-A1 protein. This result could be related to the extreme sensitivity of MSP, which can theoretically detect as few as $0.1 \%$ of cells with gene methylation (23). For the prediction of the response to the taxan-based chemotherapy, immunostaining could be a suitable method.

The biological function of MAGE proteins remains poorly understood. MAGE-A3 has been shown to bind in vitro to murine pro-caspase-12, thereby blocking the autoactivation of caspase- 9 and the downstream activation of caspase- 3 (35). The forced MAGE-A2 or MAGE-A6 expression in an ovarian cancer cell line induces the expression of the paclitaxel-resistant phenotype. These findings suggest that MAGE-A expression favors tumor cell survival and that MAGE-A proteins function as oncoproteins. In contrast, the 
forced MAGE-A1 expression increased the sensitivity to paclitaxel and docetaxel in TMK-1 cells in the present study. This result suggests that MAGE-A1 does not participate directly in the drug-resistance phenotype despite the statistical association in the GC tissue samples. It has been reported that MAGE-A4 is commonly expressed in non-small cell lung cancers and has a proapoptotic effect and can function as a tumor suppressor protein (36), indicating that functional differences within the MAGE-A family may exist. Taken together, these results suggest that not all of the cancer-testis antigen genes participate directly in the taxol resistance. As the early activation of MAGE-A genes in cancer could be due to genomewide DNA hypomethylation, which is a frequently observed epigenetic event during carcinogenesis (37), the increased expression of genes which neighbor the $M A G E-A 1$ gene could contribute directly to the taxanresistant phenotype. As we used the TMK-1 GC cell line only, the effect of forced MAGE-A1 expression on chemoresistance in other GC cell lines should be investigated.

In conclusion, the results of the present retrospective study suggest that the expression of MAGE-A1 could be a marker for the prediction of resistance to taxan-based chemotherapy in patients with GC. As the rate of MAGEA1-positive immunostaining was low in the present study, it is difficult to find a usefulness of MAGE-A1 in clinical application for the marker of the prediction of resistance to taxan-based chemotherapy in GC. A more sensitive marker is needed. A comprehensive analysis of expression of the cancer-testis antigen genes could reveal a more sensitive marker for the prediction of the response to taxan-based chemotherapy.

\section{Acknowledgements}

This study was supported, in part, by Grants-in-Aid for Cancer Research from the Ministry of Education, Culture, Science, Sports, and Technology of Japan; and from the Ministry of Health, Labor, and Welfare of Japan. We thank Masayoshi Takatani and Masayuki Ikeda for their excellent technical assistance and advice. This study was carried out with the kind cooperation of the Research Center for Molecular Medicine, Faculty of Medicine, Hiroshima University. We thank the Analysis Center of Life Science, Hiroshima University for the use of their facilities.

\section{References}

1. Yoshida K, Hirabayashi N, Takiyama W, et al: Phase I study of combination therapy with S-1 and docetaxel (TXT) for advanced or recurrent gastric cancer. Anticancer Res 24: 1843-1851, 2004.

2. Yoshida K, Ninomiya M, Takakura N, et al: Phase II study of docetaxel and S-1 combination therapy for advanced or recurrent gastric cancer. Clin Cancer Res 12: 3402-3407, 2006.

3. Ringel I and Horwitz SB: Studies with RP 56976 (taxotere): a semisynthetic analogue of taxol. J Natl Cancer Inst 83: 288-291, 1991.

4. Wada Y, Yoshida K, Suzuki T, et al: Synergistic effects of docetaxel and S-1 by modulating the expression of metabolic enzymes of 5-fluorouracil in human gastric cancer cell lines. Int J Cancer 119: 783-791, 2006.

5. Yasui W, Sentani K, Motoshita J and Nakayama H: Molecular pathobiology of gastric cancer. Scand J Surg 95: 225-231, 2006.

6. Ushijima T and Sasako M: Focus on gastric cancer. Cancer Cell 5: $121-125,2004$.
7. Yasui W, Oue N, Ito R, Kuraoka K and Nakayama H: Search for new biomarkers of gastric cancer through serial analysis of gene expression and its clinical implications. Cancer Sci 95: 385-392, 2004.

8. Oue N, Hamai Y, Mitani Y, et al: Gene expression profile of gastric carcinoma: identification of genes and tags potentially involved in invasion, metastasis, and carcinogenesis by serial analysis of gene expression. Cancer Res 64: 2397-2405, 2004.

9. Aung PP, Oue N, Mitani Y, et al: Systematic search for gastric cancer-specific genes based on SAGE data: melanoma inhibitory activity and matrix metalloproteinase-10 are novel prognostic factors in patients with gastric cancer. Oncogene 25: 2546-2557, 2006.

10. Duan Z, Feller AJ, Toh HC, Makastorsis T and Seiden MV: TRAG-3, a novel gene, isolated from a taxol-resistant ovarian carcinoma cell line. Gene 229: 75-81, 1999.

11. Feller AJ, Duan Z, Penson R, Toh HC and Seiden MV: TRAG3 , a novel cancer/testis antigen, is overexpressed in the majority of melanoma cell lines and malignant melanoma. Anticancer Res 20: 4147-4151, 2000.

12. Nimmrich I, Erdmann S, Melchers U, et al: Seven genes that are differentially transcribed in colorectal tumor cell lines. Cancer Lett 160: 37-43, 2000.

13. Chen Z, Zhu B and Wu Y: Expression of TRAG-3 antigen in non-small-cell lung carcinomas. Lung Cancer 38: 101-102, 2002.

14. Wu YZ, Zhao TT, Ni B, Zou LY, Liu HL and Zhu B: Expression of TRAG-3 in breast cancer. Int J Cancer 107: 167-168, 2003.

15. Zhu B, Chen Z, Cheng X, et al: Identification of HLA-A*0201restricted cytotoxic T lymphocyte epitope from TRAG-3 antigen. Clin Cancer Res 9: 1850-1857, 2003.

16. Duan Z, Duan Y, Lamendola DE, et al: Overexpression of MAGE/GAGE genes in paclitaxel/doxorubicin-resistant human cancer cell lines. Clin Cancer Res 9: 2778-2785, 2003.

17. Miyagawa N, Kono K, Mimura K, Omata H, Sugai H and Fujii H: A newly identified MAGE-3-derived, HLA-A24-restricted peptide is naturally processed and presented as a CTL epitope on MAGE-3-expressing gastrointestinal cancer cells. Oncology 70: 54-62, 2006.

18. Scanlan MJ, Gure AO, Jungbluth AA, Old LJ and Chen YT: Cancer/testis antigens: an expanding family of targets for cancer immunotherapy. Immunol Rev 188: 22-32, 2002.

19. Honda T, Tamura G, Waki T, et al: Demethylation of MAGE promoters during gastric cancer progression. Br J Cancer 90: 838-843, 2004.

20. Lauren P: The two histological main types of gastric carcinoma. Diffuse and so-called intestinal type carcinoma: an attempt at histological classification. APMIS 64: 31-49, 1965.

21. TNM classification of malignant tumors. Sobin LH and Wittekind $\mathrm{CH}$ (eds). 6th edition. John Wiley \& Sons, New York, pp65-68, 2002.

22. Rimoldi D, Salvi S, Reed D, et al: cDNA and protein characterization of human MAGE-10. Int J Cancer 82: 901-907, 1999.

23. Herman JG, Graff JR, Myohanen S, Nelkin BD and Baylin SB: Methylation-specific PCR: a novel PCR assay for methylation status of CpG islands. Proc Natl Acad Sci USA 93: 9821-9826, 1996.

24. Ochiai A, Yasui W and Tahara E: Growth-promoting effect of gastrin on human gastric carcinoma cell line TMK-1. Jpn J Cancer Res 76: 1064-1071, 1985.

25. Yasui W, Ayhan A, Kitadai Y, et al: Increased expression of p34cdc2 and its kinase activity in human gastric and colonic carcinomas. Int J Cancer 53: 36-41, 1993.

26. Inoue $\mathrm{H}, \mathrm{Li} \mathrm{J}$, Honda $\mathrm{M}$, et al: MAGE-1 mRNA expression in gastric carcinoma. Int J Cancer 64: 76-77, 1995.

27. Mori M, Inoue H, Mimori K, et al: Expression of MAGE genes in human colorectal carcinoma. Ann Surg 224: 183-188, 1996.

28. Utsunomiya T, Inoue H, Tanaka F, et al: Expression of cancertestis antigen (CTA) genes in intrahepatic cholangiocarcinoma. Ann Surg Oncol 11: 934-940, 2004.

29. Jung EJ, Kim MA, Lee HS, et al: Expression of family A melanoma antigen in human gastric carcinoma. Anticancer Res 25: 2105-2111, 2005.

30. Fujie T, Tahara K, Tanaka F, Mori M, Takesako K and Akiyoshi T: A MAGE-1-encoded HLA-A24-binding synthetic peptide induces specific anti-tumor cytotoxic T lymphocytes. Int J Cancer 80: 169-172, 1999.

31. Jones PA and Baylin SB: The fundamental role of epigenetic events in cancer. Nat Rev Genet 3: 415-428, 2002. 
32. Oue N, Motoshita J, Yokozaki H, et al: Distinct promoter hypermethylation of p16INK4a, CDH1, and RAR-beta in intestinal, diffuse-adherent, and diffuse-scattered type gastric carcinomas. J Pathol 198: 55-59, 2002.

33. Shutoh M, Oue N, Aung PP, et al: DNA methylation of genes linked with retinoid signaling in gastric carcinoma: expression of the retinoid acid receptor beta, cellular retinol-binding protein 1 , and tazarotene-induced gene 1 genes is associated with DNA methylation. Cancer 104: 1609-1619, 2005.

34. Oue N, Mitani Y, Motoshita J, et al: Accumulation of DNA methylation is associated with tumor stage in gastric cancer. Cancer 106: 1250-1259, 2006.
35. Morishima N, Nakanishi K, Takenouchi H, Shibata T and Yasuhiko Y: An endoplasmic reticulum stress-specific caspase cascade in apoptosis. Cytochrome c-independent activation of caspase-9 by caspase-12. J Biol Chem 277: 34287-34294, 2002.

36. Peikert T, Specks U, Farver C, Erzurum SC and Comhair SA: Melanoma antigen A4 is expressed in non-small cell lung cancers and promotes apoptosis. Cancer Res 66: 4693-4700, 2006.

37. Ehrlich M: DNA methylation in cancer: too much, but also too little. Oncogene 21: 5400-5413, 2002. 